\title{
Consumer behaviour in search of a circular economy
}

\section{Antoni Seguí-Alcaraz}

* Corresponding author: University of Valencia, Faculty of Economics, Department Applied Economics, Campus dels Tarongers, Avda. dels Tarongers, s/n, 46022 Valencia, Spain. E-mail: antoni.Segui@uv.es

\begin{abstract}
The circular economy is an alternative paradigm whose purpose is the protection of the environment, the prevention of pollution and the growth of economic prosperity. This paper covers research which is qualitative in nature but has an exploratory scope through a documentary review, and includes proposals to promote sustainability. A more responsible consumption or use can be achieved by educating the user or consumer to return the product to production or repair through a collection service by way of reverse logistics (recovery of materials), followed by recycling or reuse of the product or its components to then offer these as recovered or recycled products on the market.
\end{abstract}

Key words: circular economy, environment, consuming.

\section{Introduction}

Globalisation demands a multidisciplinary vision, not simply focused on commercial and financial processes but one that can respond to the urgent and high-impact change that the planet needs in order to accelerate the protection of ecosystems and achieve social, economic, and sustainable development for future generations. The circular economy is an alternative paradigm whose purpose is the protection of the environment, the prevention of pollution and the growth of economic prosperity, thus facilitating sustainable development (Parchomenko et al., 2019, Marrero and Espinosa, 2020).

To achieve a real impact on the current planetary situation, actions are necessary on a global scale. These actions should be founded on investigation and transmission of knowledge, policies, production processes and legislation in each country, and the adoption of a strategic vision by organisations, and all parts of society, in order to involve as many actors as possible in support of sustainability and the circular economy. 
The world at present follows a linear economic model made up of various processes; taking resources, or inputs, from the environment, producing, consuming or using, and eliminating (generating waste). This, coupled with population growth and processes contiguous with globalisation, inevitably drives an inefficient use of resources that threatens future supply (Eco-Innovation Observatory, 2016).

The circular economy is proposed as an alternative to the linear economic model. Daddi et al. (2017) state that the circular economy is restorative and regenerative, its objective being to always keep components, products, and materials at their most efficient levels of use. A circular economy is a cycle of positive continuous development that preserves and increases natural capital, optimises the yields of resources and minimises the risks of the system, managing finite stocks and renewable flows. Furthermore, its approach works on any scale.

In following a circular economy, organisations build into their strategic planning a sustainable vision in their products and processes and, by doing so, gain competitive advantages in terms of social benefits, image, and even costs, through the design of a regenerative business approach. A relationship between competitiveness, innovation and sustainability is sought by looking for ways of producing new and more attractive products, reducing costs through eco-efficiency, and implementing innovations in organisational processes that contribute to competitiveness.

Strategic planning is a process aimed at defining and pursuing objectives in order to achieve a desired state, satisfying the needs and expectations of users, collaborators and other interested parties, and with the intention of achieving lasting competitive advantages. But added to this should be a vision which incorporates responsibility for the ecosystem, at the same time bringing together the different interest groups and relationships of the organisation.

This paper covers research which is qualitative in nature but has an exploratory scope through a documentary review, and includes proposals to promote sustainability, development and the circular economy in order to improve the decision-making of modern organisations with a long-term global vision and who are concerned about the environment. 
The methodology used in the study involves a systematic review of the literature to highlight recent advances on the subject. Theoretical sources are consulted in repositories or databases, such as: Dialnet; Econlit, EBSCO; Web of Science, Journal Citation Reports and Scopus. The review is limited to the last 10 years of research on the subject.

The main objective of this paper is to analyse and contribute to the dissemination of a sustainable strategic vision which seeks socio-economic development, as well as to present the advantages or opportunities that may arise from implementing a production based on the circular economy model. It seeks to put forward proposals that an organisational level promote decision-making towards sustainability and economic, social and regenerative development. The questions, therefore, behind this study are how does the circular economy model work and how can it be implemented with a strategic vision generating changes in the consumer. 


\section{Changes in consumer behaviour for a sustainable world}

Globalisation has increased world production through business models that affect the availability of resources. This globalisation is changing the way that environmental factors are perceived, from a local or national level to a global one, thus modifying the scope of the social, political, economic, and environmental decisions that are taken.

The growing globalisation process would not be possible without advances in transport and telecommunications, generating social, economic, and cultural integration and interdependence between countries, and increasing production and economies of scale (Ahmed et al., 2019).

Globalisation, however, is changing the natural environment and its relations with man. According to Witjes \& Lozano (2018), protecting the natural world is important, but so is using its resources sensitively with a conscious effort to aid its recovery. Authorities, in many cases, have been guilty of exploitation (and overexploitation of resources), leading to a lack of control and more acute damage to the environment which, in itself, changes the livelihood of the inhabitants of a territory.

Ideally, globalisation should seek to contribute to economic and social development by meeting the basic needs of the world's inhabitants and aiming to reduce production gaps that accentuate poverty and other inequalities. Historically, regions and countries have focused on economic growth measured by production increases, using the Gross Domestic Product (GDP) as an indicator, but a more effective measurement is now called for that measures not only production and the economy but also social, environmental and general welfare factors.

As pointed out by Medaniand and. Bhandari (2019) public policies are needed that tackle local problems and improve regional economic, social and ecological conditions. This reflects the true purpose of sustainability, which is to ultimately improve communities and their quality of life, guaranteeing the maintenance of natural resources. A green economy, therefore, is one of the global strategies for dealing with the economic and environmental crises suffered by contemporary societies. Its aim is to ensure that regulatory frameworks are promoted which encourage conservation, that incentives are 
given to green sectors and industries, and that rigorous standards are put in place to control and reduce activities which affect the environment (Barbier, 2011).

In line with this, organisations with a strategic and sustainable vision need to adjust their processes so that sustainability, more than being seen as a series of short-term activities, becomes a cultural and continuous element within the organisation. This includes the implementation of initiatives such as green jobs, and a working approach by organisations, industry and reverse logistics which contributes in a sustainable way to the regeneration of ecosystems, supporting the green and circular economy and thus generating socio-economic development.

As consumers, we must value and support these emerging ecologically responsible industries that really want to deliver products with more green quality attributes, greater benefits and with less environmental impact. Some examples of these emerging industries are ecotourism, eco-construction, renewable energy generation using elements such as water, sun or wind, eco-transport and many other industries that can coexist with this vision of recycling and reuse.

First and foremost, there has to be an understanding that the business model used by the economy, based on the availability of cheap and natural resources, is unsustainable. Recent studies have highlighted that maintaining this exploitation rate will lead to an imminent shortage of natural resources in the supply chain (Witjes, \& Lozano, 2016).

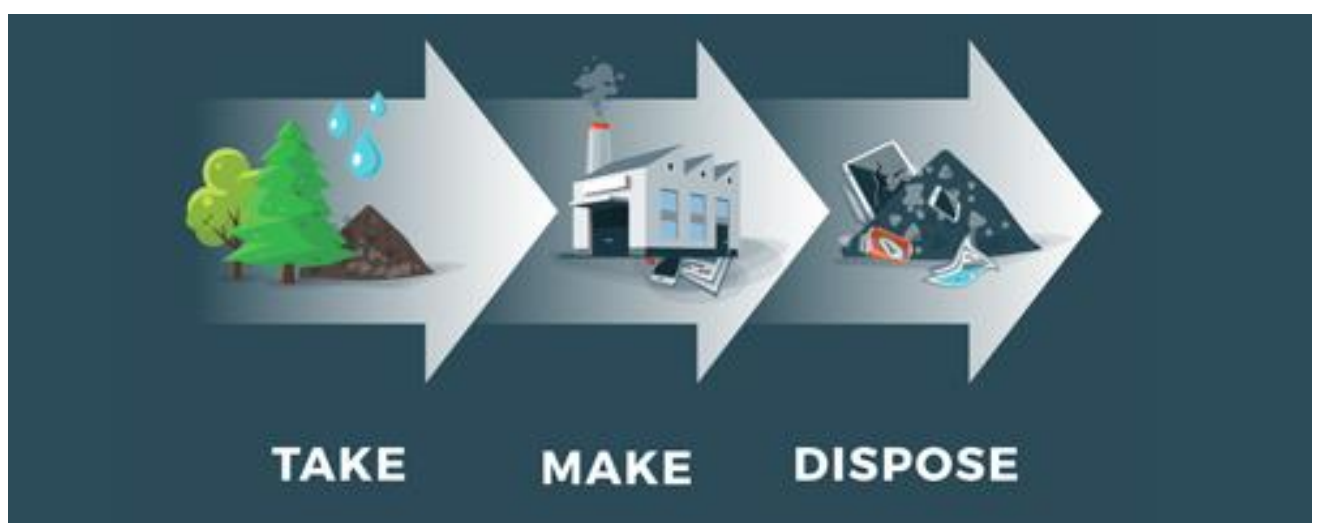

Figure 1. Stages of the linear economy. 
As shown in Figure 1, the linear economy based on extracting, producing, using and throwing away does not contribute to sustainability. For this reason, a move towards a sustainable and circular transition is necessary, as shown in Figure 2. It must start with a review of the extraction of raw materials which, in many cases, is based on the option of least cost. The ecological factor must be considered, followed by a design of processes and products that allow the reuse of materials and a production that minimises waste and other effects, such as emissions. Ultimately, the consumers need to understand how to make appropriate and extended use of the products.

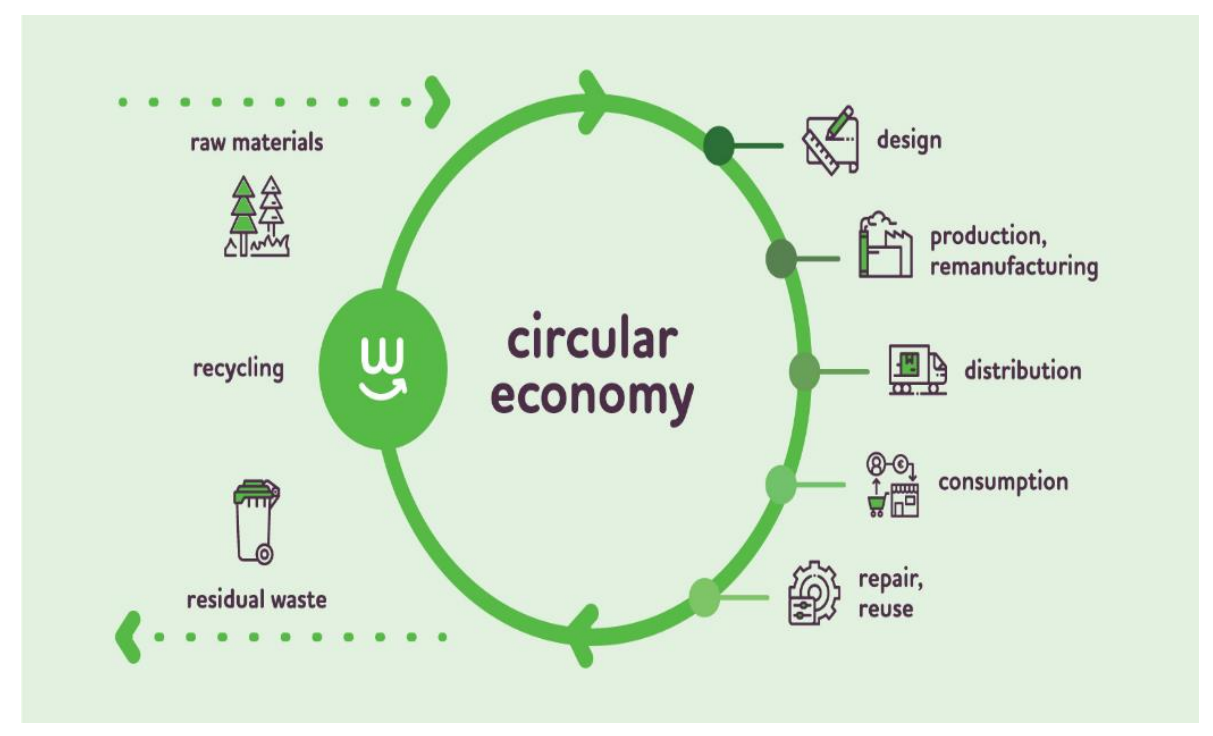

Figure 2. The circular economy.

Strengthening this proposal, Ardente et al. (2014) explain that the circular economy constitutes the framework in which eco-design is developed, as an integral circular model, from the raw material, design, manufacture, transport and distribution to the end of the product's life, whether that be through reuse or recycling.

Eco-innovation is innovation aimed at reducing environmental impact, and can be incorporated into technologies, organisations, products and complete systems (Hopkinson, et al., 2018).

Types of eco-innovation for a circular economy include: 
- Product design, allowing recovery options such as repair, maintenance, remanufacturing and recycling.

- Processes for reducing the use of materials, emissions and dangerous substances, as well as reducing risks by saving costs in production processes.

- Reorganisation of management methods and systems.

- Design, delivery, promotion and prices of products and services, such as promotion of reuse, eco-labelling and green labelling.

- Social innovations, promoting behaviour and lifestyle changes, smart consumption and responsible shopping.

- Adapting the system, introducing completely new functions to reduce the overall environmental

- $\quad$ impact, such as new urban governance, smart cities, permaculture. (EcoInnovation Observatory, 2016).

In short, the principles or contributions that the circular economy pursues include preserving and increasing natural capital, optimising the performance of resources and promoting the effectiveness of the system, seeking to eliminate negative externalities (Daddi et al., 2017).

Other contributions or benefits from the circular economy are being achieved mainly through the reuse of materials, waste or products that customers no longer use and which are reintegrated into production. These include improved safety measures in the supply of raw materials, a reduced environmental impact by reducing the extraction of raw materials, greater innovation and a better economic value from natural resources.

In addition, a circular economy promotes sustainable consumption and the opportunity for new jobs. A more sustainable consumer behaviour can be fostered through social innovation associated with "sharing", eco-design, reuse, recycling, etc., and new jobs will arise from the need for training and education. 


\section{Evaluation of circular economies}

Circular initiatives should be at the core of decisions and actions taken by people who, in turn, will apply this approach to the business world and across countries, seeking to generate a movement of greater impact on the back of globalisation.

Companies should promote eco-strategies through a planning process with objectives that always consider the impact of decisions and actions on the environment and society, with a vision towards the regeneration of the ecosystems with which the organisation interacts.

A study by the World Business Council for Sustainable Development and The Boston Consulting Group, in 2017, sets out recommendations to implement circular initiatives throughout the value cycle of companies, although it should be noted that the challenges differ according to the type of company and industry (Katz \& López, 2018).

These include the following recommendations:

- Engage with sustainability: interaction with interest groups from consumers to organisations that have their own sustainability objectives and can establish collaboration channels both in actions and training.

- Define the vision and objectives of the circular economy of the company and communicate it effectively to all those involved.

- Create a financial budget for these actions, but at the same time highlight the social and environmental benefits that offset the cost.

- Promote leadership towards sustainability and remain up to date with latest ideas in ecological design, recyclability and practices that extend the useful life of the product (Katz \& López, 2018).

- Set up sustainability departments to encourage circular economy projects, promote innovation in processes, products and even the business model while defining clear objectives with quantitative goals, responsibilities and deadlines as well as indicators that allow the results to be communicated and even to inspire others.

From the outset, products must be designed so that they have a longer useful life and are recyclable when they become waste, so that the materials used in their manufacture are 
in the economic cycle for the longest time possible and, when they become waste, they can be more easily passed through the recycling process (Franco, 2017).

However, in order to generate improvement opportunities, environmental impacts and the perception of users need to be monitored in aspects such as functionality, cost-benefit, reparability and durability. These aspects should play a bigger part in consumer acceptance of a product (Tukker, 2015).

Another important initiative is to put an end to programmed obsolescence. A fundamental premise should be to promote a more sustainable consumption and denounce these practices, backed by consumer institutions and effective policies and legislation in each country, in favour of the consumer and sustainability.

Moraci et al. (2020) define programmed obsolescence as the programmed production of products that will be obsolete in the short term due to a deficiency incorporated by the producer. It has an economic purpose, inducing customers to continually buy new versions of the product. A contribution to sustainability and the circular economy would be the reduction of these practices. This change, however, must start with the manufacturers using innovation in products and technologies to focus on a higher and more sustainable quality and then communicating this added value to consumers for these to make more informed choices.

The objective of sustainable consumption and production is to achieve more, and do it better, with fewer resources, increasing the net welfare gains of economic activities by reducing the use of resources, degradation and pollution during the entire life cycle and, at the same time, improve the quality of life (Moraci et al., 2020).

Circular initiatives should focus on: the protection of ecosystems to guarantee the existence of raw materials; the management of the various resources used in the production and logistics process; the management of waste derived from the production process; the environmental impacts derived from the consumption of the goods; and the final destination of the products after consumption or at the end of the line (reuse). 
An example of an initiative that can be applied at the business level is waste prevention. One objective is to reduce the content of harmful substances in materials and products and lessen the adverse impacts of the waste on human health and the environment, lengthening the useful life of the product by reusing it but in a sustainable way (Franco, 2017).

\section{Human influence on the circular economy}

Humans depend on healthy ecosystems to live so it is important that they protect their surroundings, now and for future generations. But the actions of consumers, business initiatives, and political decisions of countries worldwide are reflected in the impact they have on the environment. To bring about change, education or training is fundamental in promoting socio-economic development and to take advantage of the contributions of the circular economy. This approach has given rise to the term "human ecology".

Human ecology stems from human relationships: the relationship that human beings build with their environment, with other human beings, and through dialogue with themselves (Silva et al., 2019). In human interaction with the environment, education and ethical training is essential so that each individual reaches a better understanding of the impact and consequences generated through decisions and actions taken.

Environmental or ecological responsibility refers to the fact that there are numerous environmental problems with social implications. Some authors even refer to a litany of environmental issues: pollution, resource depletion, risks to biodiversity, climate change, etc. Acknowledging the role of humans is fundamental in order to improve the current situation in the world. Promoting the idea of human ecology and ecological ethics can be achieved through continuous and intensive processes, in formal educational centres or training in current organisations, as well as by encouraging organisations of global relevance to participate in this field. One initiative, received very positively, is that of the Sustainable Development Goals (SDGs), which are already in force and are having an impact, globally. All these efforts contribute to a socio-economic and sustainable development (United Nations, 2020). 
If change can be brought about in human attitude, then this is more likely to extend to companies and supply chains. For this to happen, greater effort and application is required from educational institutions, government policies and company strategies. One such element is the promotion of "green jobs". Javier Warman states that "green jobs are decent jobs that help preserve and restore the environment" (International Labor Organization, 2020, p. 4).

The International Labor Organization explains that green jobs are crucial for sustainable development and to respond to the global challenges of environmental protection, economic development and social inclusion. By involving governments, workers and employers as active agents of change, the ILO promotes the "greening" of companies (International Labor Organization, 2020).

Companies today have significant communication power and even more so with digital media, such as social networks, search engine optimisation and other forms of electronic communication. They, therefore, have the capacity to promote a campaign responsibly and, by doing so, contribute to better consumer decisions. The human role is essential in the circular economy to ensure that decisions regarding use, consumption or production can really contribute to sustainability and to ensure business eco-strategies are effective.

The circular economy and sustainability demand that organisations have a clear strategic vision that includes fundamental components, or pillars, in decisions and actions, so that planning can be effectively implemented and the scope of such a strategic and sustainable vision has a greater chance of success.

Based on the literary review and the vision of public and private organisations, this article proposes four strategic pillars on which to implement a strategy based on the circular economy. These are Immediacy, Intelligence, Innovation and Integration, as depicted in Figure 3. 


\section{Strategic Growth Pillars PPT Slide}

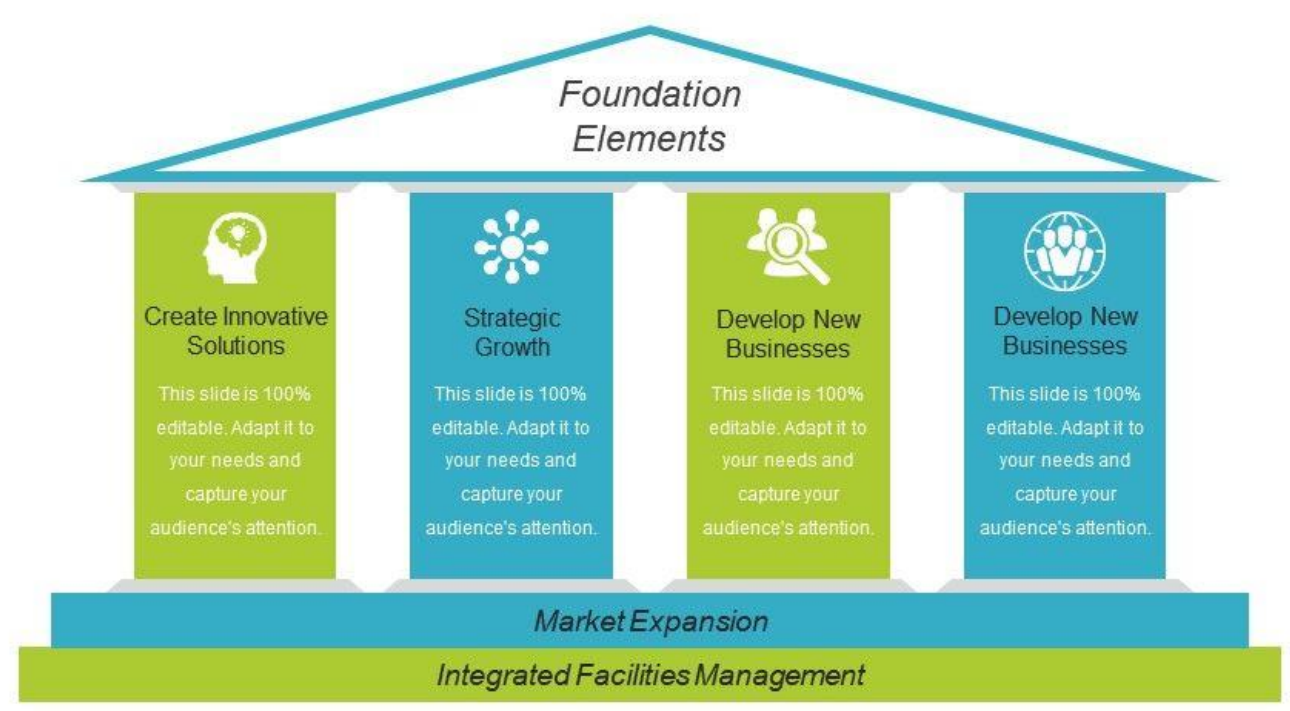

Figure 3. Strategic growth pillars.

The first pillar for an organisation to consider is Intelligence, from the point of view of the circular economy and sustainability. This organisational intelligence must be reflected in the ability to make ongoing decisions which minimise negative impacts on the environment and, ideally, contribute to ecosystems through regeneration.

This business intelligence also implies continuous learning by the members of the organisation, not only through isolated initiatives or actions but also through continuous and scalable processes. This should go beyond one-off investigations on the environment, market and emergence of new green practices, and involve a constant review of the information on these elements; how the world is today and how to continually adapt in order to meet sustainability expectations. This pillar should also take advantage of technological tools, data and research, turning them into inputs for eco-strategic decisions.

Innovation is the second pillar, necessary for green value propositions. Organisations need to innovate with green products, with new or alternative materials or with designs 
that facilitate repair, reuse or recycling. Innovation in processes should also be sought to reduce transport, energy use, and use of materials, among other aspects. Finally, innovative methods of organisation and commercialisation are called for which question and improve the way work is distributed and the way products are delivered. Today's technology can help in this respect since, for example, teleworking as a method of business organisation over various locations can reduce vehicle mobility and pollution caused by gas emissions. Likewise, the online delivery of digital products, such as books, music, movies, advertising, etc., reduces the use of materials.

The third pillar is Immediacy. Organisations must respond quickly to customer requirements before they decide to look elsewhere. The sustainable strategic vision also requires immediate decisions and actions; for the sake of the planet there is no time to waste. Although the strategic planning and operation of the company must be considered as a long-term plan, immediate actions must also be implemented that contribute to the construction of that vision.

The fourth pillar is Integration. In addition to seeking unification between the other pillars, this prompts organisations to seek integration between their internal departments and collaborators so that they might all adopt the same vision, values and policies towards sustainability. This includes tapping into human talent in developing knowledge and skills in ecological issues and passing them on to other departments or functions of the organisation. In the same way, this integration must occur with external agents, such as the company's suppliers and distributors, seeking high levels of collaboration and even demanding increasingly sustainable practices which can contribute to the circular economy.

These proposed pillars seek to offer a starting point for organisations to begin their strategic planning with a new outlook, recognising the advantages of the circular economy and the need to contribute to sustainability. 


\section{Conclusions}

The objective of this paper is to contribute to the dissemination of a more responsible strategic vision towards the environment by considering the effects of globalisation on production as well as the need to seek socio-economic development and the circular economy. This follows the realisation that the linear economic model, of taking resources from the environment, producing, consuming or using and eliminating (creating waste), is not sustainable.

The circular economy proposes that, in production processes, organisations consider the life of products through a responsible procurement of raw materials and other materials and resources. They should also carry out the design of products and processes with consideration as to how to maximise the useful life of the product through a production that reuses materials and seeks to reduce waste. Products should also be distributed using movement and transportation practices that reduce pollution. A more responsible consumption or use can be achieved by educating the user or consumer to return the product to production or repair through a collection service by way of reverse logistics (recovery of materials), followed by recycling or reuse of the product or its components to then offer these as recovered or recycled products on the market.

Reverse logistics is key to the circular economy, where Reuse, Recover and Recycle are the established concepts, based on the 3 Rs of the economic life cycle, and to which 4 more concepts have been added that make up the definition of a circular economy, calling on companies to Rethink, Redesign, Repair and Remanufacture materials, products and technologies,

In addition, the contributions of the circular economy include preserving natural capital, optimising the performance of resources and eliminating negative externalities. Models based on the circular economy have the power to replace, in the short or medium term, the traditional economic model in the search for a society without waste, founded on sustainable production and consumption practices.

Proposals, therefore, for the implementation of circular initiatives consider the following: an interaction with external interest groups that contribute ideas and objectives for sustainability; involvement of the personnel of the organisations in a consistent way; and 
communication of the concept and vision throughout the organisation so that it is fully embraced. In addition to the education of the collaborators, there should be innovation in processes followed by product and business model innovation in collaboration with external stakeholders. Finally, key indicators must be defined; adequate planning is crucial and must be clearly controlled or measured to achieve objectives that can be seen to really contribute to the circular economy.

Organisations should also promote green job initiatives, limit or restrict programmed obsolescence practices, and apply proposals such as business intelligence, immediacy, innovation and integration to effectively implement a strategy with a sustainable vision.

People play a significant role in promoting the circular economy; hence concepts such as human ecology and ecological ethics should be promoted through education and training processes in existing organisations. In addition, worldwide corporations need to generate global proposals. It is clear that sustainable, economic and social development is managed by, and for, people and organisations: their own future depends on this. As such, the implementation of the circular economy, and of a strategic and sustainable vision in modern companies, is a necessary decision. It is hoped this paper will encourage future research within the framework of new initiatives for nurturing a more sustainable planet. 


\section{References}

Ahmed Z, Wang Z, Mahmood F, Hafeez M, Ali N (2019). Does globalization increase the ecological footprint? Empirical evidence from Malaysia. Environ Sci Pollut Res 26(18):18565-18582. https://doi.org/10.1007/s11356-019-05224-9.

Ardente, F. Mathieux, F., Recchioni, M (2014). Recycling of electronic displays: analysis of pre-processing and potential ecodesign improvements. Resource, Conservation and Recycling. 92, 158-171. http://dx.doi.org/10.1016/j.resconrec.2014.09.005.

Barbier E. (2011). The policy challenges for green economy and sustainable economic development. Nat. Resour. Forum, 35 (2011), pp. 233-245, 10.1111/j.14778947.2011.01397.x.

Daddi, T., Nucci, B., \& Iraldo, F. (2017). Using Life Cycle Assessment (LCA) to measure the environmental benefits of industrial symbiosis in an industrial cluster of SMEs. Journal of Cleaner

Production, 147, 157- 164. https://doi.org/10.1016/j.jclepro.2017.01.090.

Eco-Innovation Observatory (2016). Policies and Practices for Eco-Innovation Uptake and Circular Economy Transition. European Comission: EIO bi-annual report.

Franco M.A. (2017). Circular economy at the micro level: a dynamic view of incumbents' struggles and challenges in the textile industry. J. Clean. Prod., 168 (2017), pp. 833845, 10.1016/j.jclepro.2017.09.056.

Hopkinson, P., Zils, M., Hawkins, P., \& Roper, S. (2018). Managing a complex global circular economy business model: Opportunities and challenges. California Management Review, 60(3), 71-94. https://doi.org/10.1177/0008125618764692.

International Labour Organization (2020). The Green Jobs Program of the ILO (International Labour Organization). https://www.ilo.org/global/topics/green-jobs/lang-en/index.htm. Accessed 03-05-2021.

Katz-Gerro, T., \& López Sintas, J. (2018). Mapping circular economy activities in the European Union: Patterns of implementation and their correlates in small and medium- 
sized enterprises. Business Strategy and the

Environment, 1- 12. https://doi.org/10.1002/bse.2259.

Medani P. Bhandari (2019). Sustainable Development: Is This Paradigm The Remedy of All Challenges? Does Its Goals Capture The Essence of Real Development and Sustainability? With Reference to Discourses, Creativeness, Boundaries and Institutional $\begin{array}{llll}\text { Architecture. } & \text { SocioEconomic } & \text { Challenges, } & 3(4),\end{array}$ http://doi.org/10.21272/sec.3(4).97-128.2019.

Moraci F, Errigo MF, Fazia C, Campisi T, Castelli F (2020). Cities under Pressure: Strategies and Tools to Face Climate Change and Pandemic. Sustainability.; 12(18):7743. https://doi.org/10.3390/su12187743.

Parchomenko A., Nelen D., Gillabel J. , H. Rechberger (2019). Measuring the circular economy - a multiple correspondence analysis of 63 metrics. J. Clean. Prod., 210 (2019), pp. 200-216, 10.1016/j.jclepro.2018.10.357.

Tukker A. (2015). Product services for a resource-ef fi cient and circular economy e a review. Journal Cleaner Production, 97 , pp. 76-91, 10.1016/j.jclepro.2013.11.049.

Silva, R. V, de Brito, J., Dhir, R.K., (2019). Use of recycled aggregates arising from construction and demolition waste in new construction applications. J. Clean. Prod. 236, 117629. doi.org/10.1016/j.jclepro.2019.117629

United Nations, (2020). Report of the Sustainable Development Goals. https://www.un.org/sustainabledevelopment/progress-report/. Accessed 07-06-2021.

Witjes, S., \& Lozano, R. (2016). Towards a more circular economy: proposing a framework linking sustainable public procurement and sustainable business models. Resources, Conservation and Recycling, 112(September), Elsevier, 37-44. doi:10.1016/J. 